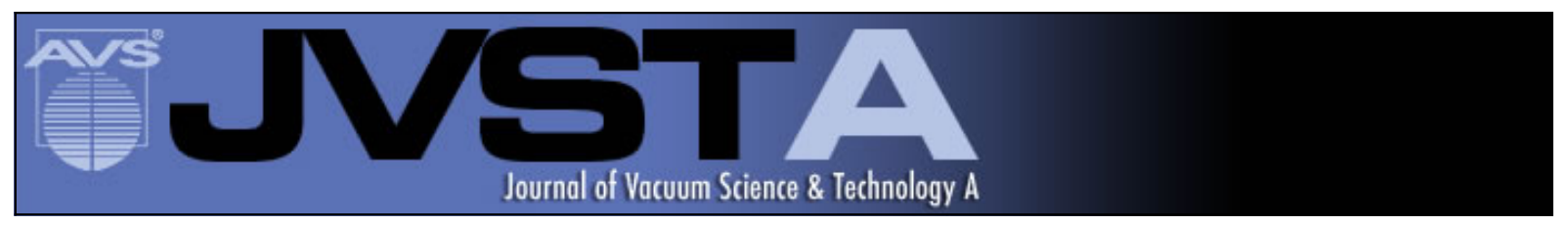

\title{
Dissociation of trimethylgallium on the ZrB2(0001) surface
}

Kedar Manandhar, Michael Trenary, Shigeki Otani, and Peter Zapol

Citation: Journal of Vacuum Science \& Technology A 31, 061405 (2013); doi: 10.1116/1.4826881

View online: http://dx.doi.org/10.1116/1.4826881

View Table of Contents: http://scitation.aip.org/content/avs/journal/jvsta/31/6?ver=pdfcov

Published by the AVS: Science \& Technology of Materials, Interfaces, and Processing

\section{Articles you may be interested in}

Influence of post-deposition annealing on interfacial properties between $\mathrm{GaN}$ and $\mathrm{ZrO} 2$ grown by atomic layer deposition

Appl. Phys. Lett. 105, 152104 (2014); 10.1063/1.4898577

Conversion of $\mathrm{CH} 4 / \mathrm{CO} 2$ to syngas over Ni-Co/Al2O3-ZrO2 nanocatalyst synthesized via plasma assisted coimpregnation method: Surface properties and catalytic performance

J. Appl. Phys. 114, 094301 (2013); 10.1063/1.4816462

1,2-Dibromoethane on $\mathrm{Cu}(100)$ : Bonding structure and transformation to $\mathrm{C} 2 \mathrm{H} 4$

J. Chem. Phys. 135, 064706 (2011); 10.1063/1.3624348

Oxidation of $\mathrm{C} 213 \mathrm{H} 5 \mathrm{O} \mathrm{H}$ by NO and $\mathrm{O} 2$ on the surface of stepped $\mathrm{Pt}(332)$ : Relationship to selective catalytic reduction of $\mathrm{NO}$ with hydrocarbons

J. Vac. Sci. Technol. A 27, 121 (2009); 10.1116/1.3054132

Kinetics of electron-induced decomposition of CF 2 Cl 2 coadsorbed with water (ice): A comparison with CCl 4 J. Chem. Phys. 121, 8547 (2004); 10.1063/1.1796551

\section{AVS $61^{\text {ST }}$ INTERNATIONAL SYMPOSIUM \& EXHIBITION}

\section{November 9-14, $2014 \Rightarrow$ Baltimore, Maryland}
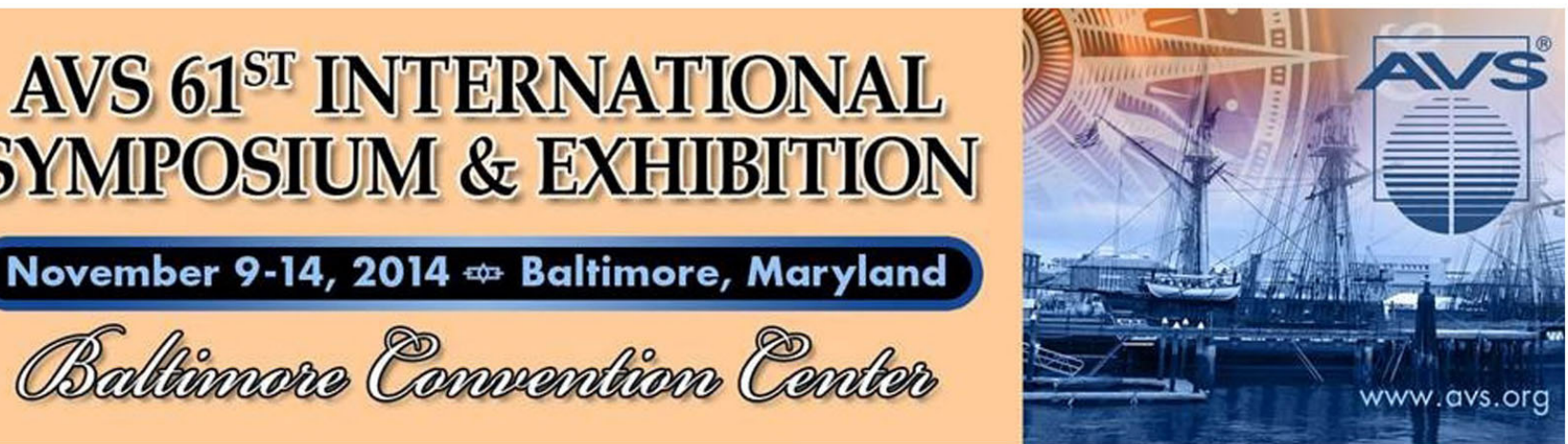


\title{
Dissociation of trimethylgallium on the $\mathrm{ZrB}_{2}(0001)$ surface
}

\author{
Kedar Manandhar and Michael Trenary ${ }^{\text {a) }}$ \\ Department of Chemistry, University of Illinois at Chicago, 845W Taylor St., Chicago, Illinois 60607 \\ Shigeki Otani \\ National Institute for Material Science, 1-1 Namiki, Tsukuba-shi, Ibaraki 305-0044, Japan \\ Peter Zapol \\ Materials Science Division, Argonne National Laboratory, 9700 S. Cass Ave., Argonne, Illinois 60439
}

(Received 1 August 2013; accepted 11 October 2013; published 29 October 2013)

\begin{abstract}
X-ray photoelectron spectroscopy and reflection absorption infrared spectroscopy (RAIRS) have been used to study the dissociative adsorption of trimethylgallium (TMG) on the $\mathrm{ZrB}_{2}(0001)$ surface. Spectra were obtained as a function of annealing temperature following TMG exposure at temperatures of 95 and $300 \mathrm{~K}$, and also as a function of TMG exposure for a surface temperature of $300 \mathrm{~K}$. After annealing above $220 \mathrm{~K}$, a significant decrease in the relative concentration of carbon and gallium occurred accompanied by a shift of $\sim 0.2 \mathrm{eV}$ in the $\mathrm{Ga} 2 \mathrm{p}_{3 / 2}$ binding energy. The RAIR spectra show that after annealing to $\sim 220 \mathrm{~K}$, only one $\mathrm{CH}_{3}$ deformation band at $1196 \mathrm{~cm}^{-1}$ remains, the intensity of which is considerably decreased indicating loss of at least one methyl group from TMG. Further annealing leads to the sequential loss of the other methyl groups. The first methyl desorbs while the last two dissociate to deposit two $\mathrm{C}$ atoms per TMG molecule onto the $\mathrm{ZrB}_{2}$ surface. (C) 2013 American Vacuum Society. [http://dx.doi.org/10.1116/1.4826881]
\end{abstract}

\section{INTRODUCTION}

Over the past few decades, III-V compound semiconductors have received remarkable interest due to their application in a wide variety of electronic and optoelectronic devices owing to their superior material properties. ${ }^{1,2}$ In particular, $\mathrm{GaN}$ is used in blue light-emitting diodes (LEDs) for various applications such as indoor/outdoor illumination, displays, automobile headlights, and in high-power and high-frequency electronics. ${ }^{1-3}$ For commercial devices, GaN is typically prepared as a thin film heteroepitaxially grown on sapphire, $\mathrm{SiC}$, or $\mathrm{Si}$. However, the mismatch of lattice constant and thermal expansion coefficient between these substrates and GaN is large, which results in strained films with a high density of threading dislocations. ${ }^{4}$ These dislocations are carrier scatterers, ${ }^{5}$ trap centers, ${ }^{6,7}$ and leakage current sources ${ }^{8,9}$ and therefore degrade device performance. In addition, structural strain may lead to the formation of cracks and to strong built-in electrostatic fields. ${ }^{10,11}$ Therefore, a substrate material that closely matches the nitride's lattice constant and thermal expansion coefficient is highly desirable. ${ }^{12}$ Recently, $\mathrm{ZrB}_{2}$, a refractory compound with good lattice constant and thermal expansion matching with GaN, has been proposed as a viable substrate for epitaxial $\mathrm{GaN}$ growth. ${ }^{12-14}$ Furthermore, $\mathrm{ZrB}_{2}$ is reflective and metallic, and its use as a substrate in LEDs minimizes loss of light and simplifies the device geometry as $\mathrm{ZrB}_{2}$ can be used as one of the ohmic contacts. ${ }^{15}$ The crystal structure of bulk $\mathrm{ZrB}_{2}$ is simple hexagonal with alternating layers of boron and zirconium as shown in Fig. 1. Therefore, the (0001) surface of $\mathrm{ZrB}_{2}$ can be terminated with either a $\mathrm{Zr}$ or B layer. Previous studies have indicated that $\mathrm{Zr}$ termination is

$\overline{{ }^{a} \text { Electronic mail: mtrenary@uic.edu }}$ thermodynamically more stable than B termination, ${ }^{16-18}$ also in agreement with the predictions for $\mathrm{HfB}_{2} .{ }^{19}$

GaN has been grown successfully on the $\mathrm{ZrB}_{2}(0001)$ surface using molecular beam epitaxy, ${ }^{13}$ pulsed-laser deposition, ${ }^{20}$ and metal organic chemical vapor deposition (MOCVD). ${ }^{21}$ Trimethylgallium (TMG) is an important precursor for GaN MOCVD. Several previous studies have examined the reaction of TMG on silicon, ${ }^{22-27} \mathrm{GaAs},{ }^{28,29}$ and other $^{30}$ surfaces. TMG adsorption on silicon ${ }^{22-26}$ and platinum $^{30}$ leads to incorporation of one mole of carbon per mole of TMG, whereas TMG on GaAs leads to no carbon buildup. $^{28}$ More recently, plasma enhanced atomic layer deposition of GaN on $\mathrm{Si}$ surfaces using TMG and $\mathrm{NH}_{3}$ was reported in which low temperature $\left(185^{\circ} \mathrm{C}\right)$ growth was achieved without significant carbon incorporation in the bulk of the GaN film. ${ }^{31}$ The dissociation of TMG and ammonia above $\mathrm{GaN}$ and $\mathrm{InN}$ surfaces has been the subject of previous computational studies; ${ }^{32,33}$ yet, the corresponding experimental identification of the surface reaction paths and intermediates is lacking. In our present work, step-by-step dissociation of $\mathrm{TMG}$ on the $\mathrm{ZrB}_{2}(0001)$ surface is investigated with $\mathrm{x}$-ray photoelectron spectroscopy (XPS) and reflection absorption infrared spectroscopy (RAIRS).

The experiments reported here involved heating the surface briefly to higher temperatures after initial TMG exposures at two different surface temperatures, 95 and $300 \mathrm{~K}$. At $95 \mathrm{~K}, \mathrm{TMG}$ adsorbs without dissociation so that RAIRS and XPS data characteristic of molecular TMG adsorbed on the surface can be obtained. Upon annealing to higher temperatures, changes in the molecularly adsorb TMG can be detected and the temperature at which dissociation begins can be determined. Exposures at a temperature, such as $300 \mathrm{~K}$, above where dissociation occurs, involve a more dynamic situation with dissociation of TMG and desorption of dissociation products occurring at the same time, which 

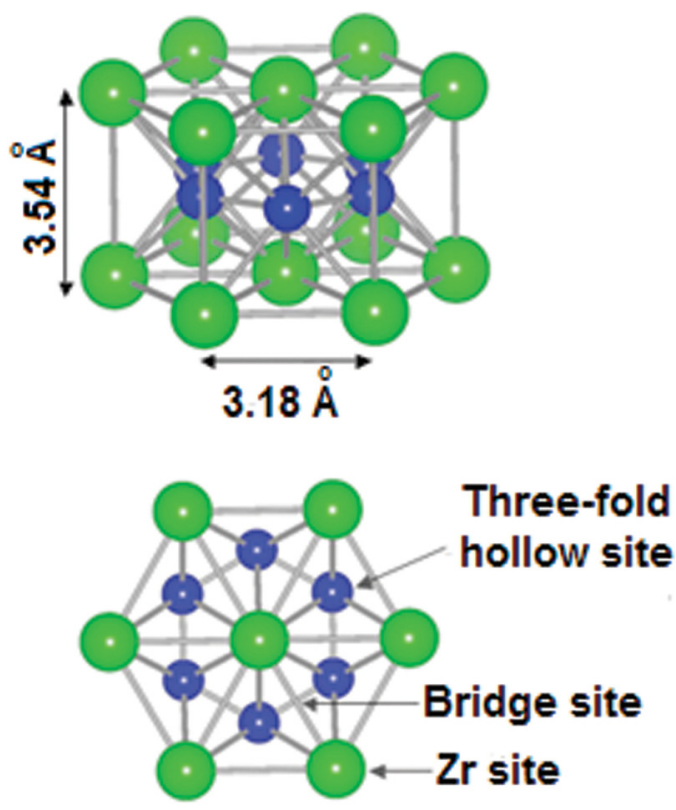

Fig. 1. (Color online) Side and top views of the $\mathrm{ZrB}_{2}(0001)$ surface with $\mathrm{Zr}$ and $\mathrm{B}$ atoms represented by large and small spheres respectively. Reprinted with permission from Manandhar et al., Surf. Sci. 615, 110 (2013). Copyright, 2013 Elsevier.

can produce different species and different coverages than obtainable following a low temperature exposure. As it is thought that the initial stages of growth control the morphology of the resultant film, the results here provide important insights into the suitability of TMG for MOCVD growth of $\mathrm{GaN}$ films on $\mathrm{ZrB}_{2}$ substrates.

\section{EXPERIMENT}

The experiments were performed in a stainless steel ultrahigh vacuum chamber with a base pressure of $1 \times 10^{-10}$ Torr. The system has been described in detail elsewhere. ${ }^{34}$ In brief, the chamber is equipped with a hemispherical electron energy analyzer (VG Microtech, Ltd., CLAM2) with a dual $\mathrm{Mg} / \mathrm{Al}$ anode $\mathrm{x}$-ray source (VG Microtech) for XPS studies, reverse view low energy electron diffraction (LEED) optics (Princeton Research Instruments, RV 8-120SH), and a commercial Fourier transform infrared spectrometer (Mattson, RS-10000).

The $\mathrm{ZrB}_{2}(0001)$ single crystal was in the form of a square-shaped disk, approximately $1 \mathrm{~cm}$ on a side and about $2 \mathrm{~mm}$ thick. It was grown as described elsewhere ${ }^{35}$ and was cut and polished to a mirror finish at the National Institute for Materials Science in Tsukuba, Japan, by methods similar to those described by Aizawa et al. ${ }^{36}$ The crystal mounting and cleaning procedures have been described previously. ${ }^{37,38}$ The clean $\mathrm{ZrB}_{2}(0001)$ surface gave a sharp $(1 \times 1)$ LEED pattern and XPS spectra free of peaks due to any elements other than $\mathrm{Zr}$ and $\mathrm{B}$ and with binding energies (BEs) in good agreement with previous studies. ${ }^{39-41}$ All XPS spectra were taken at a $15^{\circ}$ angle between the analyzer and the surface normal using $\mathrm{Mg} \mathrm{K} \alpha$ radiation and a constant analyzer pass energy of $50 \mathrm{eV}$ corresponding to a nominal resolution of $1.32 \mathrm{eV}$. XPS core level peaks were fitted by using IGOR
Pro (Wavemetrics, Inc.) software with the Shirley background removal method. The RAIR spectra were acquired with a resolution of $4 \mathrm{~cm}^{-1}$ and 1024 scans using a mercury cadmium telluride detector. In cases where the crystal was annealed above $95 \mathrm{~K}$ or room temperature (RT), it was cooled back down to $95 \mathrm{~K}$ or RT before acquiring the spectra. All background spectra were also acquired at either $95 \mathrm{~K}$ or room temperature. The epipure grade TMG was purchased from SAFC Hitech and used without further purification. Gas exposures are given in units of Langmuir (L), where $1 \mathrm{~L}=1 \times 10^{-6}$ Torr s. For the annealing experiments, the sample was heated to the desired temperature and held there for $\sim 2$ min.

\section{RESULTS AND DISCUSSION}

\section{A. RAIR spectra}

Figures 2(a), 2(b) and 3(a) show RAIR spectra obtained as a function of annealing temperature following 0.5 and $0.15 \mathrm{~L}$ TMG exposures at 95 and $300 \mathrm{~K}$, respectively. The plots in Figs. 2(c) and 3(b) show the RAIRS peak areas from Figs. 2(a) and 3(a) as a function of annealing temperature. In Figs. 2(a) and 2(b), the peaks observed at $\sim 1172,1196$, 2901 , and $2960 \mathrm{~cm}^{-1}$ are assigned by comparison with the literature values in Table I. ${ }^{23,30,42,43}$ The pair of bands with centers at 1172 and $1196 \mathrm{~cm}^{-1}$ correspond to $\mathrm{CH}_{3}$ symmetric deformations $\left(\delta_{\mathrm{s}}\right), 2901 \mathrm{~cm}^{-1}$ to a $\mathrm{CH}_{3}$ symmetric stretch $\left(\nu_{\mathrm{s}}\right)$, and $2960 \mathrm{~cm}^{-1}$ to a $\mathrm{CH}_{3}$ asymmetric stretch $\left(\nu_{\mathrm{as}}\right)$. The intensities of all peaks are unchanged from 95 to $190 \mathrm{~K}$ [Fig. 2(c)]. After annealing above $190 \mathrm{~K}$, only one weak $\delta_{\mathrm{s}}\left(\mathrm{CH}_{3}\right)$ peak at $1196 \mathrm{~cm}^{-1}$ remains [Fig. 2(a)]. Annealing further up to $270 \mathrm{~K}$ did not change the intensity or position of this peak [Figs. 2(a) and 2(c)].

Figure 3(a) shows sharp and broad peaks centered at 999 and $1221 \mathrm{~cm}^{-1}$, respectively. These peaks are assigned by comparison with the literature values. The sharp peak at $999 \mathrm{~cm}^{-1}$ agrees well with the $\mathrm{Zr}-\mathrm{H}$ stretch vibration observed following exposure of $\mathrm{ZrB}_{2}(0001)$ to $\mathrm{H}_{2}(\mathrm{~g}){ }^{36,37} \mathrm{In}$ an IR study of TMG on a silicon dioxide surface, Mawhinney et al. reported a shift of $\sim 11 \mathrm{~cm}^{-1}$ toward higher frequency for $\delta_{\mathrm{s}}\left(\mathrm{CH}_{3}\right)$ and $\delta_{\mathrm{as}}\left(\mathrm{CH}_{3}\right)$, which they attributed to the loss of one $\mathrm{CH}_{3}$ group as TMG was transformed to dimethylgallium (DMG). ${ }^{44}$ Furthermore, the intensities of the IR peaks of the $\mathrm{CH}_{3}$ groups of DMG were much weaker than those of TMG. The broad feature at $1221 \mathrm{~cm}^{-1}$ is $25 \mathrm{~cm}^{-1}$ higher than the highest $\delta_{\mathrm{s}}\left(\mathrm{CH}_{3}\right)$ peak at $1196 \mathrm{~cm}^{-1}$ [Fig. 2(a)]. Although this might imply formation of DMG here, XPS results imply loss of two methyl groups to form monomethylgallium (MMG) and the $\sim 1221 \mathrm{~cm}^{-1}$ peak is assigned to $\delta_{\mathrm{s}}\left(\mathrm{CH}_{3}\right)$ of this species. In the temperature range between $\sim 555$ and $\sim 700 \mathrm{~K}$, this band disappears [Figs. 3(a) and 3(b)], and a final shift in the Ga $2 \mathrm{p}_{3 / 2}$ XPS peak, along with a significant reduction in the intensity of the $\mathrm{C} 1 \mathrm{~s}$ peak of $\mathrm{CH}_{3}$ bonded to Ga [Figs. 6(a) and 6(b)], occurs. The Zr-H stretch peak intensity is fairly constant up to $\sim 500 \mathrm{~K}$ [Fig. 3(c)]. Upon further annealing, the peak gradually decreases in intensity and then disappears at $\sim 595 \mathrm{~K}$ [Figs. 3(a) and 3(b)], which is consistent with our 

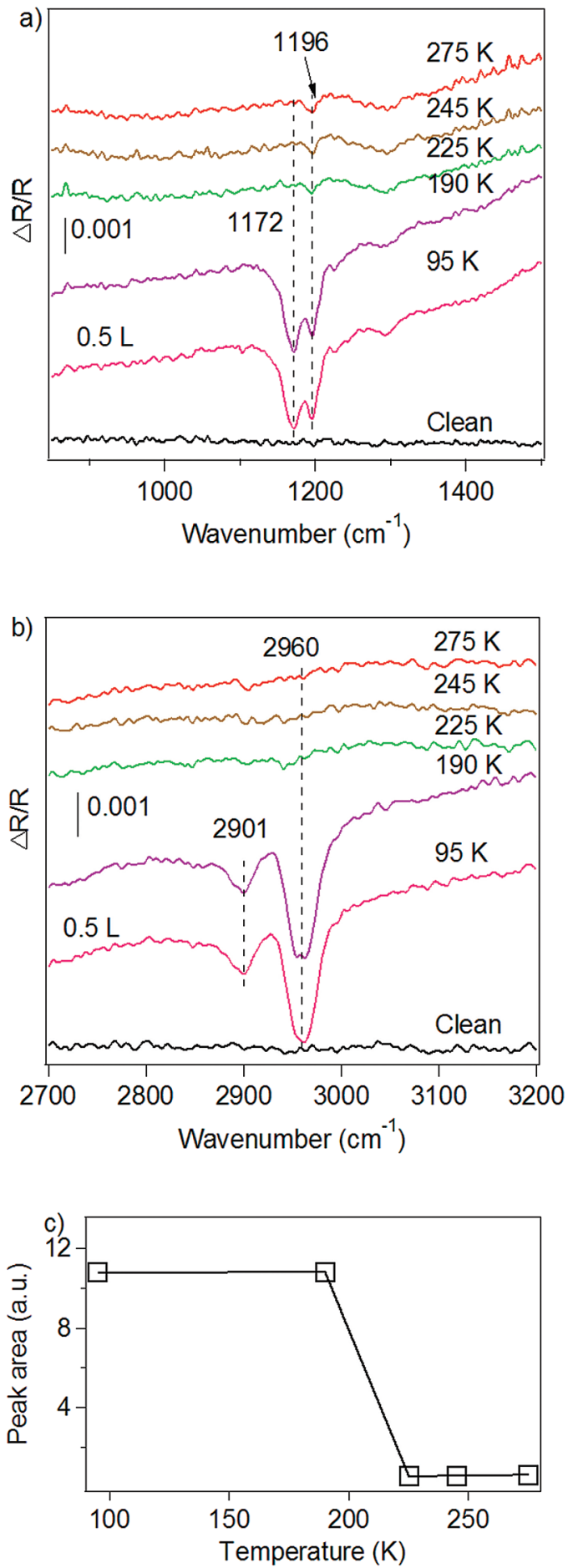

FIG. 2. (Color online) RAIR spectra of the $\mathrm{CH}_{3}$ (a) deformation ( $\delta_{\mathrm{s}}$ and $\delta_{\text {as }}$ ) and (b) stretch $\left(\nu_{\mathrm{s}}\right.$ and $\left.\nu_{\mathrm{as}}\right)$ regions as a function of annealing temperature following a $0.5 \mathrm{~L}$ TMG exposure at $95 \mathrm{~K}$. (c) Plot of RAIRS peak intensity vs annealing temperature from (a).

recent report of a hydrogen desorption temperature from $\mathrm{ZrB}_{2}(0001)$ of $\sim 625 \mathrm{~K}^{37}$ The approximately $30 \mathrm{~K}$ lower desorption temperature compared to the value in Ref. 37 is probably due to the coadsorption of carbon and gallium here. The observation of a $\mathrm{Zr}-\mathrm{H}$ stretch following TMG exposure at $300 \mathrm{~K}$ in Fig. 3(a), but not after annealing to $280 \mathrm{~K}$ after exposure at $95 \mathrm{~K}$ in Fig. 2(a), along with observation of a peak at $1195 \mathrm{~cm}^{-1}$ in the latter case attributable to surface
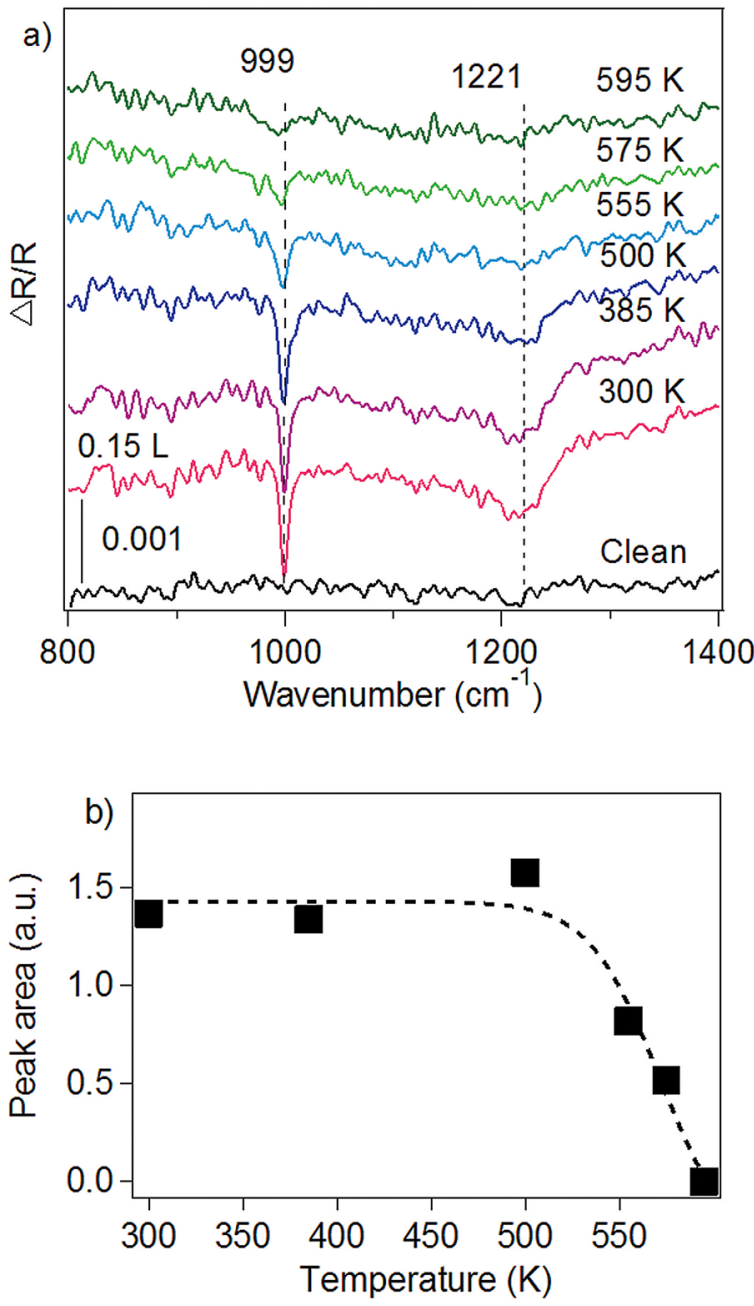

FIG. 3. (Color online) (a) RAIR spectra of the $\mathrm{CH}_{3}$ deformation $\left(\delta_{\mathrm{s}}\right.$ and $\left.\delta_{\text {as }}\right)$ and $\mathrm{Zr}-\mathrm{H}$ stretch regions as a function of annealing temperature following a $0.15 \mathrm{~L}$ TMG exposure at $95 \mathrm{~K}$. (b) Plot of $\mathrm{Zr}-\mathrm{H}$ RAIRS peak intensity vs annealing temperature.

methyl groups, suggests that $\mathrm{CH}_{3}$ dissociates at a temperature between 280 and $300 \mathrm{~K}$ to produce surface hydrogen and carbon.

\section{B. XPS results for TMG exposures at $95 \mathrm{~K}$ followed by annealing to higher temperatures}

Figure 4 shows C 1s (a), Ga 2p $3 / 2$ (b), B 1s/Zr 3d (c), XPS spectra and relative concentration $(\mathrm{RC})$ plots for boron, zirconium, carbon, and gallium as a function of annealing temperature (d) for TMG exposed to the $\mathrm{ZrB}_{2}(0001)$ surface at $95 \mathrm{~K}$. In all $\mathrm{C} 1 \mathrm{~s}$ spectra except in the one taken after the $280 \mathrm{~K}$ anneal, a shoulder at $\sim 2 \mathrm{eV}$ toward high binding energy (HBE) accompanies the main peak [Fig. 4(a)]. The origin for this shoulder is unknown.

To evaluate the thickness of the overlayers and to estimate ranges of the desorption temperature for molecular TMG only and for TMG fragments, the RCs of overlayer and substrate elements are calculated after each anneal to the temperatures used in Figs. 4(a)-4(c) and are plotted in Fig. 4(d). The concentration of an element is calculated from integrated peak areas weighted over the photoelectron 
TABLE I. Vibrational modes $\left(\mathrm{cm}^{-1}\right)$ of TMG observed here and in the literature.

\begin{tabular}{lcccccc}
\hline \hline Mode & TMG/ZrB $_{2}$ (this work) & TMG/Si(100) HREELS & TMG/Pt(111) HREELS $^{\mathrm{b}}$ & Solid (IR) $^{\mathrm{c}}$ & Liquid (Raman) $^{\mathrm{d}}$ & Gas (IR) $^{\mathrm{e}}$ \\
\hline$\nu_{\mathrm{s}}\left(\mathrm{CH}_{3}\right)$ & 2901 & 2950 & 2940 & $2898\left(\mathrm{E}^{\prime}\right)$ & $2903\left(\mathrm{~A}_{1}^{\prime}\right)$ \\
$\nu_{\text {as }}\left(\mathrm{CH}_{3}\right)$ & 2960 & 2950 & 2940 & $2955\left(\mathrm{E}^{\prime}\right)$ & $2961\left(\mathrm{E}^{\prime \prime}\right)$ \\
$\delta_{\mathrm{s}}\left(\mathrm{CH}_{3}\right)$ & 1172,1196 & 1240 & 1180 & $1168\left(\mathrm{E}^{\prime}\right)$ & $1198\left(\mathrm{E}_{1}^{\prime}\right)$ & $1198\left(\mathrm{E}^{\prime}\right)$ \\
\hline
\end{tabular}

${ }^{\mathrm{a}}$ Reference 23 .

${ }^{\mathrm{b}}$ Reference 30 .

${ }^{\mathrm{c}}$ Reference 42.

${ }^{\mathrm{d}}$ Reference 43 .

${ }^{\mathrm{e}}$ Reference 43.

escape depth and by its XPS sensitivity factor. ${ }^{45}$ The RC percentage of an element is calculated assuming the sum of the RCs of all detected elements is $100 \%$. To obtain the RCs, we used both the $3 d_{5 / 2}$ and $3 d_{3 / 2}$ components of the $\mathrm{Zr} 3 \mathrm{~d}$ peak but only the $2 p_{3 / 2}$ component of the Ga $2 p$ peak. The RCs of boron, zirconium, gallium, and carbon for clean $\mathrm{ZrB}_{2}$ are, respectively, $58 \%, 42 \%, 0 \%$, and $0 \%$, which upon exposing to $0.5 \mathrm{~L}$ of $\mathrm{TMG}$ are $\sim 0 \%, 3 \%, 25 \%$, and $72 \%$, respectively [Fig. 4(d)]. Although the stoichiometry implies that the RCs of $\mathrm{B}$ and $\mathrm{Zr}$ for the clean surface should be $67 \%$ and $33 \%$, respectively, because the top layer is $\mathrm{Zr}$, with the first boron layer below the surface, the $\mathrm{Zr}: \mathrm{B}$ ratio from the RCs is slightly higher than would be obtained for a homogeneous distribution of the two elements over the escape depth of the
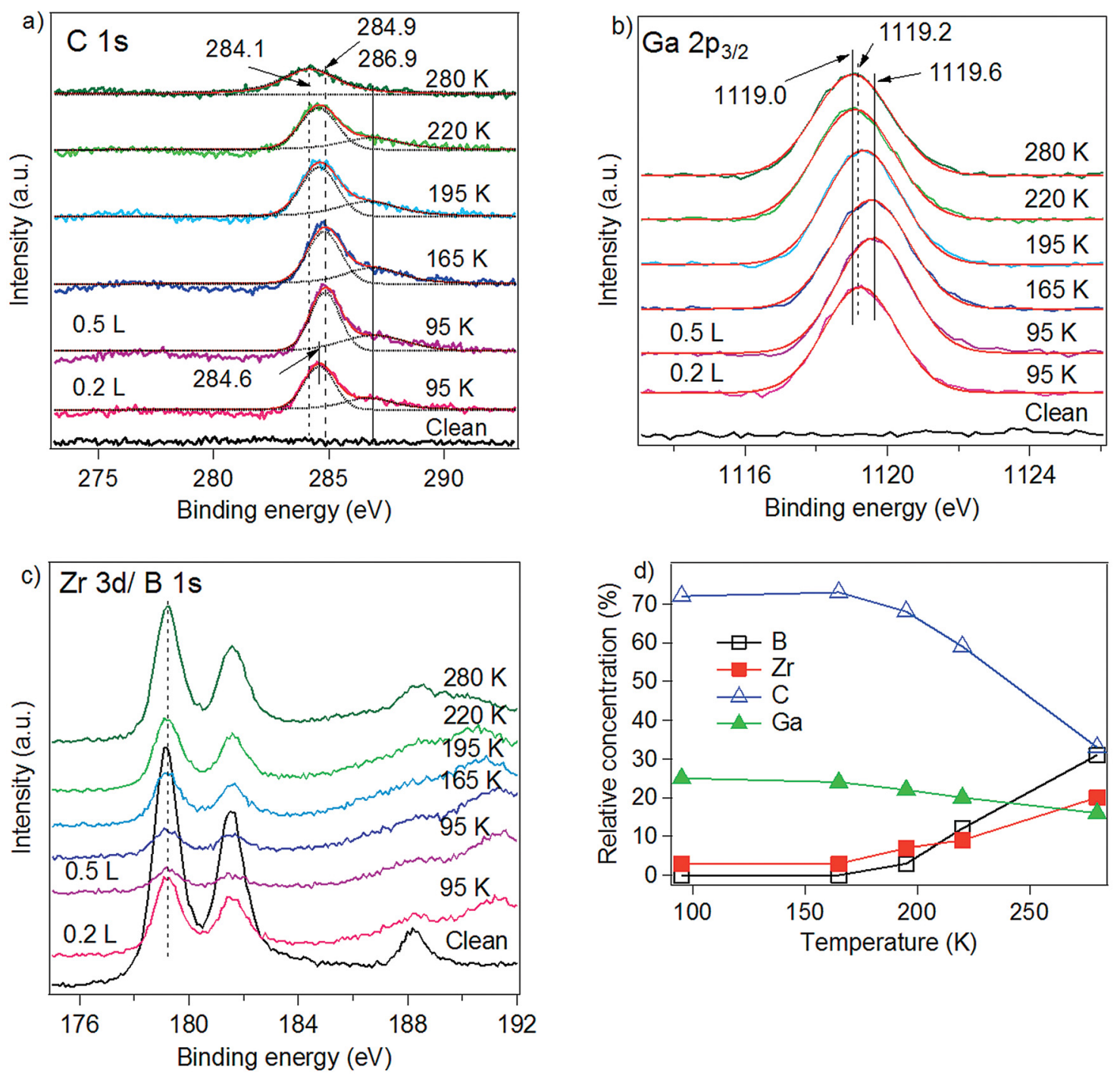

FIG. 4. (Color online) XPS spectra of the (a) $\mathrm{C} 1 \mathrm{~s}$, (b) Ga 2 $\mathrm{p}_{3 / 2}$ (c) $\mathrm{Zr} 3 \mathrm{~d} / \mathrm{B}$ 1s regions as a function of annealing temperature following exposure to $0.5 \mathrm{~L}$ of TMG in two steps on $\mathrm{ZrB}_{2}(0001)$ at $95 \mathrm{~K}$. The black dashed and red solid curves in (a) are the fitted components and their sum, respectively. (d) Plots of relative concentration of boron (black line with open squares), zirconium (red line with filled squares), gallium (green line with filled triangles), and carbon (blue line with open triangles) as a function of annealing temperature. 
photoelectrons. From 95 to $165 \mathrm{~K}$, there is no change in the RCs of boron, zirconium, gallium, or carbon. After annealing in steps to $220 \mathrm{~K}$, the boron and zirconium RCs slightly increase while the carbon and gallium RCs slightly decrease. The carbon and gallium RCs are respectively, $\sim 59 \%$ and $\sim 20 \%$. The ratio of carbon to gallium on the $\mathrm{ZrB}_{2}$ surface is still $\sim 3$, suggesting molecular desorption of TMG. After annealing to $280 \mathrm{~K}$, as before, the RCs of zirconium and boron increase and that of carbon and gallium decrease. The RCs of both carbon and gallium are, respectively, $33 \%$ and $16 \%$. The ratio of carbon to gallium is now $\sim 2$ implying a loss of a methyl group from TMG and carbon desorption, presumably in the form of methane from the reaction of methyl with residual hydrogen on the surface or in the form of ethane from the combination of two methyl groups. The RCs of boron and zirconium after the $280 \mathrm{~K}$ anneal are $\sim 31 \%$ and $20 \%$, respectively [Fig. 4(d)]. These values are smaller by a factor of $1.8 \pm 0.4$ compared to the measured $\mathrm{RCs}$ of boron and zirconium when TMG was exposed at $300 \mathrm{~K}$ [Fig. 5(d)]. These RCs imply, for similar TMG
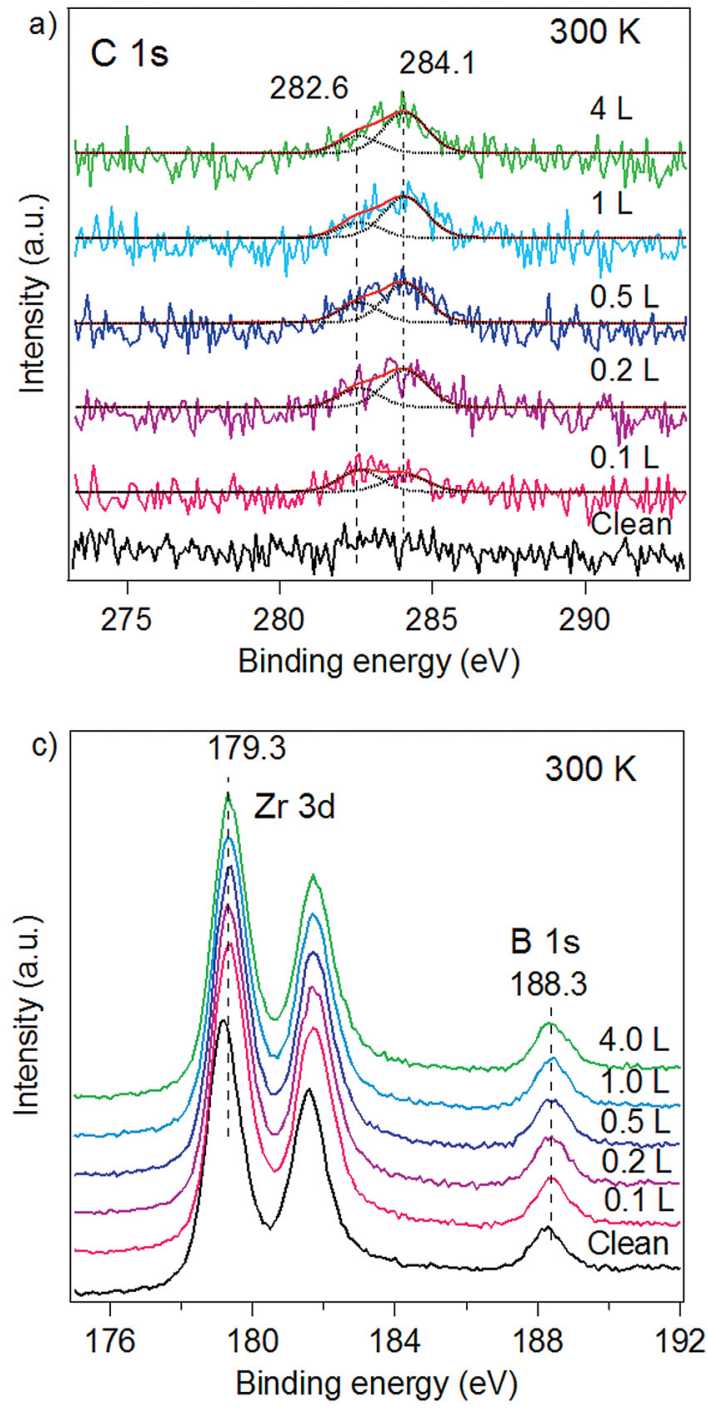

exposures, that the overlayer thickness obtained by exposing at $300 \mathrm{~K}$ is less than the residual thickness after annealing to $280 \mathrm{~K}$ following exposure at $95 \mathrm{~K}$. Molecular desorption of TMG from 165 to $220 \mathrm{~K}$ and breaking of a $\mathrm{Ga}-\mathrm{CH}_{3}$ bond after annealing above $220 \mathrm{~K}$ is supported by the RAIR spectra [Figs. 2(a) and 2(b)]. After annealing to $\sim 225 \mathrm{~K}$, the $\nu_{\mathrm{s}}\left(\mathrm{CH}_{3}\right)$ and $\nu_{\mathrm{as}}\left(\mathrm{CH}_{3}\right)$ peaks at 2901 and $2960 \mathrm{~cm}^{-1}$, respectively, disappear and the intensities of the $\delta_{\mathrm{s}}\left(\mathrm{CH}_{3}\right)$ peaks at 1172 and $1196 \mathrm{~cm}^{-1}$ decrease considerably leaving only a weak peak at $1196 \mathrm{~cm}^{-1}$.

In Fig. 4(a), the $\mathrm{C}$ 1s peak shifts to HBE with exposure and to lower binding energy (LBE) with annealing temperature. For overlayers formed from a $0.2 \mathrm{~L}$ exposure, the $\mathrm{BE}$ of the main $\mathrm{C}$ 1s peak is at $284.6 \mathrm{eV}$ [Fig. 4(a)]. The BE of this peak shifts $+0.3 \mathrm{eV}$ for a $0.5 \mathrm{~L}$ exposure. Upon annealing in steps, the BE of the main peak gradually shifts back toward lower binding energies and is at $284.1 \mathrm{eV}$ after heating to $280 \mathrm{~K}$. As the overlayer thickness gradually decreases upon annealing above $95 \mathrm{~K}$, a higher/lower C $1 \mathrm{~s} \mathrm{BE}$ is evidently related to a thicker/thinner overlayer. This is similar to an
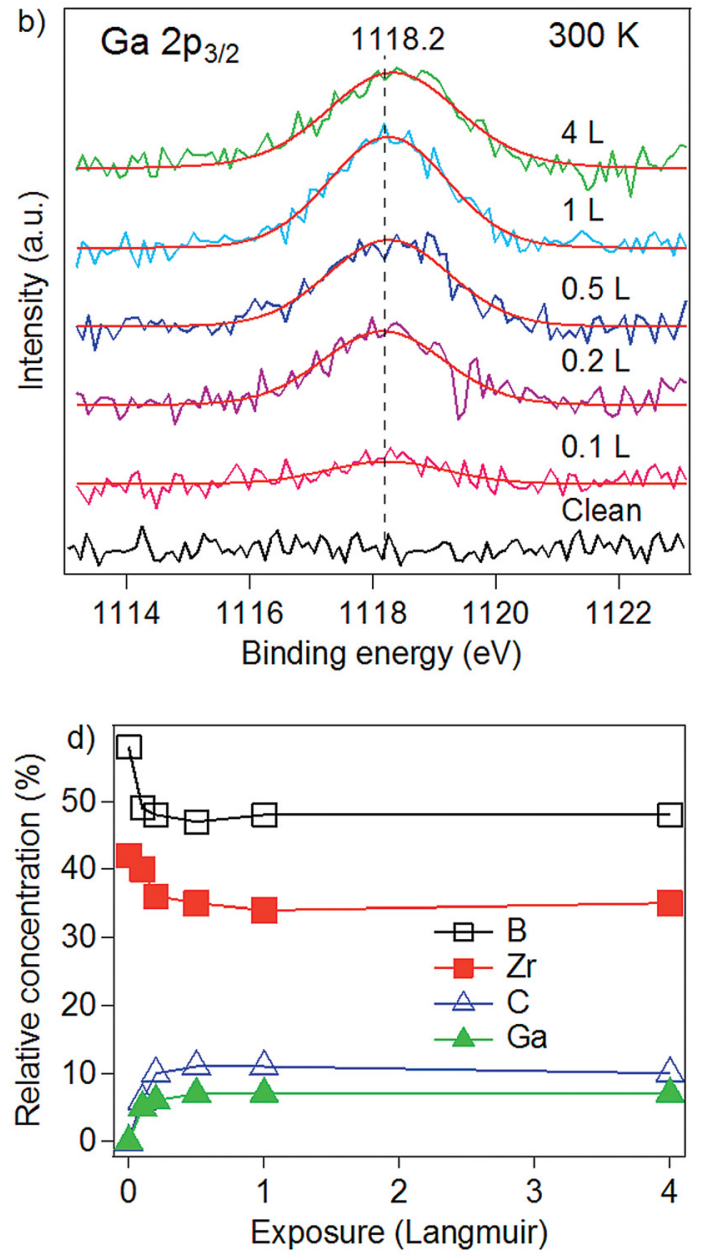

FIG. 5. (Color online) XPS spectra in the (a) C 1s, (b) Ga 2p $\mathrm{p}_{3 / 2}$ (c) B 1s/Zr 3d regions as a function of TMG exposure at $300 \mathrm{~K}$. The black dashed and red solid curves in (a) are the fitted components and their sum, respectively. (d) Plots of relative concentration of boron (black line with open squares), zirconium (red line with filled squares), gallium (green line with filled triangles), and carbon (blue line with open triangles) as a function of TMG exposure. 
observation of the relative shift of the $\mathrm{C} 1 \mathrm{~s} \mathrm{BE}$ toward $\mathrm{HBE} / \mathrm{LBE}$ values when the thickness of a methane multilayer increases/decreases on $\mathrm{Pt}(111) .{ }^{46}$ A BE shift dependence on overlayer thickness is also observed for the Ga $2 p_{3 / 2}$ peak. For a $0.2 \mathrm{~L}$ TMG exposure, the $\mathrm{Ga} 2 \mathrm{p}_{3 / 2} \mathrm{BE}$ is at $1119.2 \mathrm{eV}$. Upon increasing the exposure to $0.5 \mathrm{~L}$, the $\mathrm{Ga}$ $2 \mathrm{p}_{3 / 2}$ peak shifts by $\sim+0.4$ to $1119.6 \mathrm{eV}$, which after annealing gradually shifts toward LBE and reaches $1119.0 \mathrm{eV}$ after a $280 \mathrm{~K}$ anneal. It is noteworthy that Lee $\mathrm{et} \mathrm{al} .^{23}$ and Shogen et $a l{ }^{47}$ in their XPS studies of TMG decomposition on $\mathrm{Si}(100)$ and $\mathrm{Si}(111)$, respectively, reported that the Ga core levels are $\sim 0.2 \mathrm{eV}$ lower for DMG than for TMG. In Fig. 4(b), the shift in the Ga $2 p_{3 / 2}$ peak is gradual, so it is not straightforward to establish a temperature range for TMG decomposition and hence to determine a shift related to TMG partial dissociation. Since partial dissociation of TMG occurs between 220 and $280 \mathrm{~K}$, we believe a shift of the Ga $2 \mathrm{p}_{3 / 2}$ peak of $\sim 0.2 \mathrm{eV}$ toward LBE in Fig. $4(\mathrm{~b})$ is related to the partial dissociation of TMG. In the higher temperature $(>280 \mathrm{~K})$ experiments (explained below), there are two more significant shifts observed in the Ga $2 \mathrm{p}_{3 / 2}$ peak toward LBE. These shifts are indicative of further loss of $\mathrm{CH}_{3}$ from $\mathrm{Ga}$, so we suggest that a $\mathrm{Ga} 2 \mathrm{p}_{3 / 2} \mathrm{BE}$ of $\sim 1119 \mathrm{eV}$ is associated with $\mathrm{DMG}$ on the $\mathrm{ZrB}_{2}(0001)$ surface.

The $\mathrm{C}$ 1s peak obtained after annealing TMG exposed at 95 to $280 \mathrm{~K}$ is symmetric with the peak centered at $284.1 \mathrm{eV}$ [Fig. 4(b)]. A $284.1 \mathrm{eV}$ component also exists in the $\mathrm{C} 1 \mathrm{~s}$ spectra taken after exposing TMG at $300 \mathrm{~K}$ [Fig. 5(a)]. We attribute the peak centered at $284.1 \mathrm{eV}$ to $\mathrm{C} 1 \mathrm{~s}$ of a $\mathrm{CH}_{3}$ group still bonded to Ga.

\section{XPS results for TMG exposures at $300 \mathrm{~K}$}

Figure 5 shows XPS spectra and a plot of RCs as a function of TMG exposure at $300 \mathrm{~K}$. The RCs of zirconium and boron initially decrease while those of gallium and carbon increase. After an exposure of $\sim 0.5 \mathrm{~L}$ of TMG, the RCs of zirconium, boron, gallium, and carbon are, respectively, 34\%, 47\%, 6\%, and $13 \%$. For longer exposure, almost no change in any of the RCs occurs indicating saturation of the $\mathrm{ZrB}_{2}$ surface and in particular that a TMG multilayer does not form. At saturation, the decrease in the RCs of zirconium and boron relative to their values for the clean surface is $\sim 10 \pm 3 \%$. Therefore, unlike nitrogen, which adsorbs at a three-fold hollow site resulting in a large decrease in the boron RC but a very small change in the zirconium $\mathrm{RC}$ when ammonia was exposed to $\mathrm{ZrB}_{2}$ at $\mathrm{RT},{ }^{38}$ the adsorbates here, which consist of the products of TMG dissociation, evidently do not prefer the three-fold hollow sites. The $\mathrm{C} 1 \mathrm{~s}$ peaks are asymmetric with the main peak (HBE component) and shoulder (LBE component) centered at 284.1 and $282.6 \mathrm{eV}$, respectively. The intensity of the shoulder is almost constant for all exposures while that of the main peak gradually increases at the beginning and then levels off at an exposure of $0.5 \mathrm{~L}$.

As for the TMG exposures at $95 \mathrm{~K}$, for all exposures at $300 \mathrm{~K}$, the $\mathrm{Zr} 3 \mathrm{~d}_{5 / 2}, \mathrm{Zr} 3 \mathrm{~d}_{3 / 2}$, and $\mathrm{B} 1 \mathrm{~s}$ peaks are symmetric. However, after the first exposure of $0.1 \mathrm{~L}$, the centers of the zirconium and boron peaks are shifted by $\sim 0.1 \mathrm{eV}$ toward higher $\mathrm{BE}$ compared to their values for the clean surface [Fig. 5(c)]. The peak positions do not change with increasing exposure. Similarly, the Ga $2 \mathrm{p}_{3 / 2}$ peak is symmetric for all exposures. The peak is centered at $\sim 1118.2 \mathrm{eV}$, which is $0.8 \mathrm{eV}$ lower than the measured value of $1119.0 \mathrm{eV}$ of $\mathrm{Ga}$ $2 \mathrm{p}_{3 / 2}$ at $280 \mathrm{~K}$. A significant shift in Ga BEs toward lower values as gallium becomes more metallic (fewer $\mathrm{CH}_{3}$ ) was reported in the decomposition of TMG on $\mathrm{Si}(100)$ and $\mathrm{Si}(111){ }^{22,47}$ Therefore, observation of a shift in Ga $2 \mathrm{p}_{3 / 2}$ by $-0.8 \mathrm{eV}$ in the $300 \mathrm{~K}$ spectra compared to those taken at $280 \mathrm{~K}$ suggests that gallium is more metallic when TMG is exposed to the $\mathrm{ZrB}_{2}$ surface at $300 \mathrm{~K}$ than when the system of $\mathrm{TMG} / \mathrm{ZrB}_{2}$ prepared at $95 \mathrm{~K}$ is annealed to $280 \mathrm{~K}$. As there is a final shift in the Ga $2 p_{3 / 2}$ BE further toward lower values when the $T M G / \mathrm{ZrB}_{2}$ system prepared at $300 \mathrm{~K}$ is annealed to higher temperatures, we assign the $1118.2 \mathrm{eV}$ BE peak to Ga $2 p_{3 / 2}$ of MMG.

The LBE component of $\mathrm{C} 1 \mathrm{~s}$ at $282.6 \mathrm{eV}$ observed here is close to the $\mathrm{BE}$ of carbon bonded to a $\mathrm{Si}(100)$ surface, $282.5 \mathrm{eV} .{ }^{22}$ Therefore, we attribute the $282.6 \mathrm{eV}$ component to carbon bonded to the $\mathrm{ZrB}_{2}$ surface. This assumption is further supported by the fact that the only remaining $\mathrm{C}$ 1s peak after annealing above $1025 \mathrm{~K}$ is at $282.6 \mathrm{eV}$ [Fig. 6(a)]. After annealing above $1025 \mathrm{~K}$, gallium desorbs from the surface, implying that the remaining carbon is bonded directly to the $\mathrm{ZrB}_{2}$ surface. The $\mathrm{BE}$ of the $\mathrm{C} 1 \mathrm{~s}$ main peak at $284.1 \mathrm{eV}$ is $\sim 1.5 \mathrm{eV}$ higher than the $\mathrm{BE}$ of the shoulder at $282.6 \mathrm{eV}$. The $\mathrm{BE}$ of the symmetric $\mathrm{C} 1 \mathrm{~s}$ peak in the spectrum taken after annealing to $280 \mathrm{~K}$ in Fig. 4(a) is also $284.1 \mathrm{eV}$. Based on the explanation above, TMG has partially decomposed to form MMG. A constant C 1s BE for one to three methyl groups bonded to gallium has been reported in studies of the dissociation of TMG on silicon surfaces. ${ }^{22,23,47}$ We therefore attribute the $\mathrm{C} 1 \mathrm{~s}$ peak centered at $284.1 \mathrm{eV}$ in Fig. 5(a) to a $\mathrm{CH}_{3}$ group still bonded to Ga. This assignment is supported by observation with RAIRS of the $\delta_{\mathrm{s}}\left(\mathrm{CH}_{3}\right)$ peak corresponding to MMG at $\sim 1221 \mathrm{~cm}^{-1}$ from TMG exposure at $300 \mathrm{~K}$.

\section{XPS results for TMG exposure at $300 \mathrm{~K}$ and annealing to higher temperatures}

Figure 6 shows XPS results following annealing to the indicated temperatures after a $1.5 \mathrm{~L}$ TMG exposure to the $\mathrm{ZrB}_{2}(0001)$ surface at $300 \mathrm{~K}$. As in Fig. 5(a), the C 1s spectrum has two components at 282.6 and $284.2 \mathrm{eV}$. The $\mathrm{C} 1 \mathrm{~s}$ component of the Ga-bound carbon decreases significantly after annealing at $565 \mathrm{~K}$. The apparent reappearance of this peak in the $1025 \mathrm{~K}$ spectrum [Fig. 6(a)] is probably due to noise. For all the spectra, within experimental error, the total C 1s intensity is constant [Fig. 6(d)]. This implies that the $\mathrm{CH}_{3}$ that splits off from the gallium binds to the $\mathrm{ZrB}_{2}$ surface and spontaneously dissociates to $\mathrm{C}$ and $\mathrm{H}$ atoms.

Following the $300 \mathrm{~K}$ exposure but before annealing, the Ga $2 p_{3 / 2}$ BE is $1118.3 \mathrm{eV}$, which agrees with the value in Fig. 5(b), within experimental error. There is no BE shift up to $435 \mathrm{~K}$. A significant decrease of the $\mathrm{Ga} 2 \mathrm{p}_{3 / 2} \mathrm{BE}$ is observed after the sample is annealed to $565 \mathrm{~K}$ and this decrease continues for annealing up to $725 \mathrm{~K}$. At $725 \mathrm{~K}$, the 

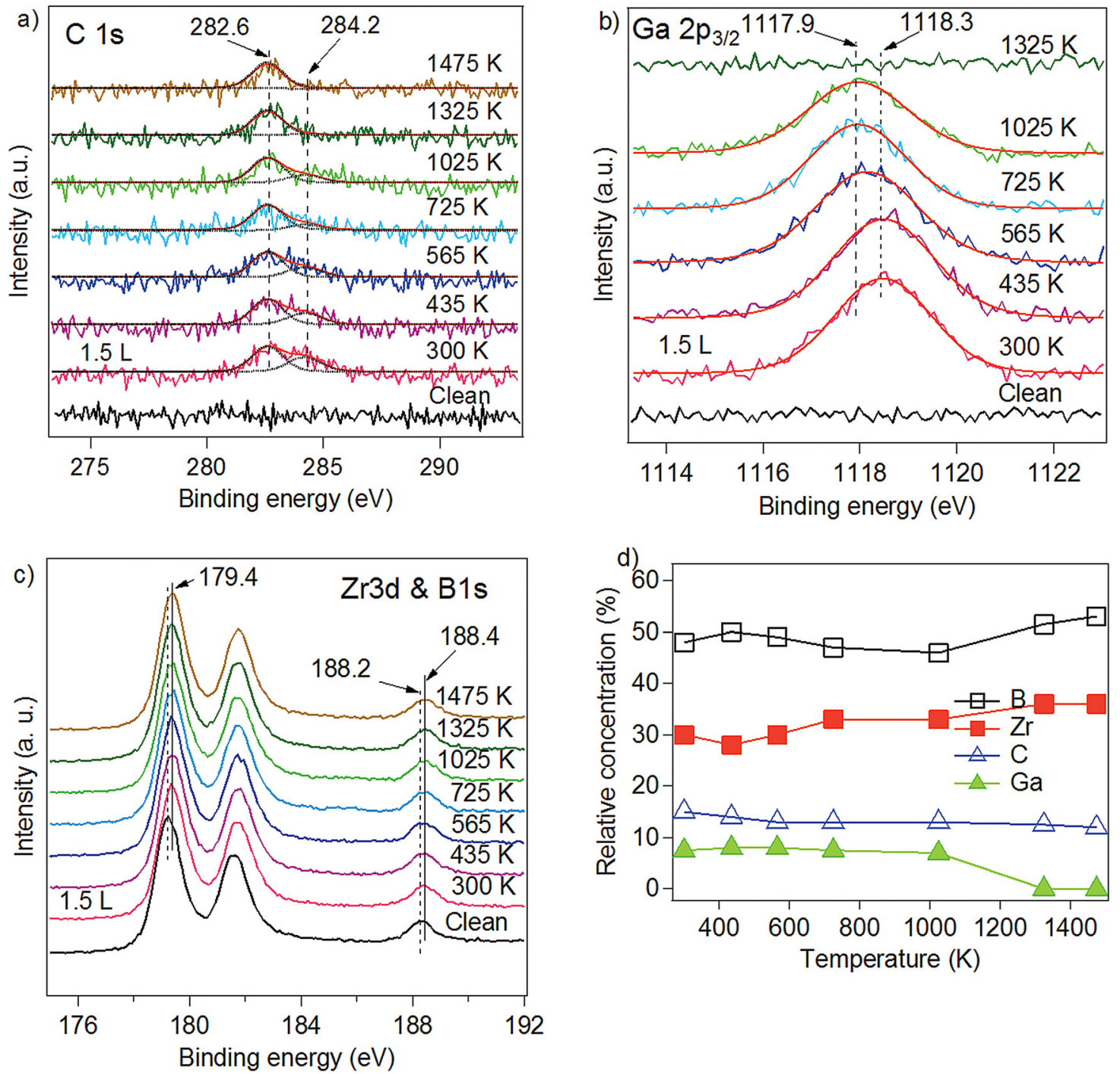

FIG. 6. (Color online) XPS spectra in the (a) $\mathrm{C} 1 \mathrm{~s}$, (b) $\mathrm{Ga} 2 \mathrm{p}_{3 / 2}$, (c) B $1 \mathrm{~s} / \mathrm{Zr} 3 \mathrm{~d}$ regions as a function of annealing temperature following exposure of $1.5 \mathrm{~L}$ of TMG on $\mathrm{ZrB}_{2}(0001)$ at $300 \mathrm{~K}$. The black dashed and red solid curves in (a) are the fitted components and their sum, respectively. (d) Plots of relative concentration of boron (black line with open squares), zirconium (red line with filled squares), gallium (green line with filled triangles), and carbon (blue line with open triangles) as a function of annealing temperature.

$\mathrm{Ga} 2 \mathrm{p}_{3 / 2} \mathrm{BE}$ is $1117.9 \mathrm{eV}$. This observation suggests that at $\sim 565 \mathrm{~K}$ breaking of the last gallium-methyl bonds begins. This assumption is supported by the disappearance of the broad $\delta_{\mathrm{s}}\left(\mathrm{CH}_{3}\right)$ RAIRS peak centered at $\sim 1221 \mathrm{~cm}^{-1}$ after annealing to $555 \mathrm{~K}$ [Fig. 3(a)] and also by the disappearance of the $284.2 \mathrm{eV}$ component of the $\mathrm{C}$ 1s peak in Fig. 6(a). A high dissociation temperature of $\sim 565 \mathrm{~K}$ for the last $\mathrm{Ga}-\mathrm{CH}_{3}$ bond agrees quite well with a similar high temperature (above $495 \mathrm{~K}$ ) reported in studies of TMG on various surfaces. ${ }^{23,25,30}$ As for TMG exposure at $300 \mathrm{~K}$, the $\mathrm{Zr} 3 \mathrm{~d}$ and $\mathrm{B} 1 \mathrm{~s}$ peaks are shifted $\sim 0.2 \mathrm{eV}$ toward $\mathrm{HBE}$ after exposing TMG, and there is no further shift upon annealing to the temperatures indicated in Fig. 6(c). Thus, the initial shift in the $\mathrm{Zr} 3 \mathrm{~d}$ and $\mathrm{B} 1 \mathrm{~s}$ peaks upon exposure at $300 \mathrm{~K}$ is attributed to the bonding of atomic carbon to the $\mathrm{ZrB}_{2}$ surface from either the partial or complete dissociation of TMG.

The XPS results should, in principle, be sensitive to the form of the carbon deposited onto the surface following either exposure at room temperature or after annealing to high temperature. In Fig. 6(a), a single C 1s peak at $282.6 \mathrm{eV}$ remains after annealing the surface to $1475 \mathrm{~K}$ after TMG deposition at $300 \mathrm{~K}$. This value is consistent with formation of $\mathrm{ZrC}$, as the $\mathrm{C} 1 \mathrm{~s}$ BEs for metal carbides generally fall in this range. ${ }^{48}$ It is not consistent with formation of graphitic carbon, which has a C 1s BE of $284.5 \mathrm{eV} .^{48}$ The $\mathrm{C} 1 \mathrm{~s}$ peak in boron carbide shows two components at 281.8 and $283.7 \mathrm{eV}$, with the former having twice the intensity of the latter. ${ }^{49}$ Within the limited signal-to-noise ratio in Fig. 6 for the $\mathrm{C}$ 1s peak, the results seem more consistent with the formation of zirconium carbide than boron carbide. Because the amount of carbon is so small, little change in the $\mathrm{Zr} 3 \mathrm{~d}$ or B 1 s peaks is seen. Also, the expected chemical shifts for these peaks upon the formation of even a large amount of carbide of either B or Zr would likely be too small to detect. If the formation of $\mathrm{ZrC}$ produced elemental boron at the surface, a B 1s peak at less than $188 \mathrm{eV}$ would be expected but is not seen. ${ }^{50}$ 
The XPS results therefore imply that residual carbon bonds to $\mathrm{Zr}$ in a way that does not substantially alter the bonding within the $\mathrm{ZrB}_{2}$ substrate.

From the above results, it is unambiguous that decomposition of TMG on the $\mathrm{ZrB}_{2}$ surface results in carbon incorporation. Furthermore, carbon on the $\mathrm{ZrB}_{2}(0001)$ surface neither desorbed nor diffused into the bulk even after annealing to $\sim 1500 \mathrm{~K}$, which is well above the temperature used for MOCVD growth of GaN. It is therefore possible that the deposited carbon may affect the morphology and defect density in films grown on $\mathrm{ZrB}_{2}$ surfaces from TMG. Previous studies demonstrated that the primary source of carbon impurities in MOCVD grown III-V semiconductors is the metal alkyl precursors. ${ }^{51,52}$ Several studies reported dramatic reductions in carbon incorporation in compounds such as GaAs and GaN when triethylgallium (TEG) is used as the gallium source instead of TMG. ${ }^{53-55}$ Similarly, using TEG could lead to reduced carbon deposition on $\mathrm{ZrB}_{2}$ substrates used for GaN growth.

\section{SUMMARY AND CONCLUSION}

We used XPS and RAIRS to investigate the dissociation of TMG on the $\mathrm{ZrB}_{2}(0001)$ surface. Consistent with results in other systems in which the gallium core levels shift toward LBE as gallium becomes more metallic, similar shifts in the Ga $2 p_{3 / 2}$ peak are observed here. In addition to Ga $2 p_{3 / 2}$ XPS BE shifts, C 1s XPS and RAIR spectra confirmed a stepwise dissociation of the gallium-methyl bonds. TMG is adsorbed molecularly at $95 \mathrm{~K}$ and it does not dissociate up to $220 \mathrm{~K}$. Upon annealing above $220 \mathrm{~K}$, TMG becomes more metallic via breaking of gallium-methyl bonds and eventually becomes completely metallic after all three $\mathrm{Ga}-\mathrm{C}$ bonds are broken. At temperatures between 220 and $280 \mathrm{~K}$, loss of a methyl group from TMG produces DMG. The symmetric $\mathrm{C}$ 1s peak obtained after annealing to $280 \mathrm{~K}$ suggests desorption of methyl. Between 280 and $565 \mathrm{~K}$, DMG further dissociates to MMG. Upon exposure of TMG to the surface at $300 \mathrm{~K}$, a $\mathrm{Zr}-\mathrm{H}$ stretch at $999 \mathrm{~cm}^{-1}$ is observed with RAIRS and an asymmetric $\mathrm{C} 1 \mathrm{~s}$ peak with a component corresponding to carbon bonded to the $\mathrm{ZrB}_{2}$ surface $(282.6 \mathrm{eV})$ is observed with XPS. These observations indicate that at $300 \mathrm{~K}, \mathrm{Ga}_{-} \mathrm{CH}_{3}$ bonds are broken and that the resulting surface methyl groups immediately dissociate to produce $\mathrm{C}$ and $\mathrm{H}$ atoms on the surface. Between 565 and $725 \mathrm{~K}$, the last $\mathrm{Ga}-\mathrm{CH}_{3}$ bond is broken. In this temperature range, the $\mathrm{Ga} / \mathrm{carbon}$ concentration ratio is essentially constant implying that the last methyl also produces $\mathrm{C}$ atoms bound to the $\mathrm{ZrB}_{2}$ surface. Hydrogen desorbs from the surface at around $595 \mathrm{~K}$ and gallium desorbs between $1025 \mathrm{~K}$ and $1323 \mathrm{~K}$ while carbon remains to at least $1475 \mathrm{~K}$. The incorporated carbon is removed only by sputtering. Dissociation of TMG on the $\mathrm{ZrB}_{2}$ surface results in two moles of carbon incorporation per one mole of TMG, making carbon incorporation an intrinsic part of the surface chemistry.

\section{ACKNOWLEDGMENTS}

This work was supported by the U.S. Department of Energy, Office of Science, Office of Basic Energy Sciences-
Materials Science under Contract No. DE-AC02-06CH11357. K.M. and M.T. also acknowledge partial support from the National Science Foundation under grant CHE-1012201.

${ }^{1}$ O. Ambacher, J. Phys. D: Appl. Phys. 31, 2653 (1998).

${ }^{2}$ H. Morkoc, Handbook of Nitride Semiconductors and Devices (WileyVCH Verlag, Weinheim, Germany, 2009).

${ }^{3}$ S. Nakamura, S. Pearton, and G. Fasol, The Blue Laser Diode: The Complete Story (Springer-Verlag, Berlin, 2000).

${ }^{4}$ S. C. Jain, M. Willander, J. Narayan, and R. V. Overstraeten, J. Appl. Phys. 87, 965 (2000).

${ }^{5}$ N. G. Weimann, L. F. Eastman, D. Doppalapudi, H. M. Ng, and T. D. Moustakas, J. Appl. Phys. 83, 3656 (1998).

${ }^{6}$ S. M. Lee, M. A. Belkhir, X. Y. Zhu, Y. H. Lee, Y. G. Hwang, and T. Frauenheim, Phys. Rev. B 61, 16033 (2000).

${ }^{7}$ S. J. Rosner, E. C. Carr, M. J. Ludowise, G. Girolami, and H. I. Erikson, Appl. Phys. Lett. 70, 420 (1997).

${ }^{8}$ P. Kozodoy, J. P. Ibbetson, H. Marchand, P. T. Fini, S. Keller, J. S. Speck, S. P. DenBaars, and U. K. Mishra, Appl. Phys. Lett. 73, 975 (1998).

${ }^{9}$ B. S. Simpkins, E. T. Yu, P. Waltereit, and J. S. Speck, J. Appl. Phys. 94, 1448 (2003).

${ }^{10}$ S. Ghosh, P. Waltereit, O. Brandt, H. T. Grahn, and K. H. Ploog, Phys. Rev. B 65, 075202 (2002).

${ }^{11}$ J. Seo Im, H. Kollmer, J. Off, A. Sohmer, F. Scholz, and A. Hangleiter, Phys. Rev. B 57, R9435 (1998).

${ }^{12}$ R. Liu, A. Bell, F. A. Ponce, S. Kamiyama, H. Amano, and I. Akasaki, Appl. Phys. Lett. 81, 3182 (2002).

${ }^{13}$ J. Suda and H. Matsunami, J. Cryst. Growth 237, 1114 (2002).

${ }^{14}$ H. Kinoshita, S. Otani, S. Kamiyama, H. Amano, I. Akasaki, J. Suda, and H. Matsunami, Jpn. J. Appl. Phys. 40, L1280 (2001).

${ }^{15}$ A. H. Blake et al., J. Appl. Phys. 111, 033107 (2012).

${ }^{16}$ X. Zhang, X. Luo, J. Li, J. Han, W. Han, and C. Hong, Comp. Mater. Sci. 46, 1 (2009).

${ }^{17}$ T. Aizawa, W. Hayami, and S. Otani, Phys. Rev. B 65, 024303 (2001).

${ }^{18}$ P. L. Liu, A. V. G. Chizmeshya, J. Kouvetakis, and I. S. T. Tsong, Phys. Rev. B 72, 245335 (2005).

${ }^{19}$ K. Yamamoto, K. Kobayashi, H. Kawanowa, and R. Souda, Phys. Rev. B 60, 15617 (1999).

${ }^{20}$ Y. Kawaguchi, J. Ohta, A. Kobayashi, and H. Fujioka, Appl. Phys. Lett. 87, 221907 (2005).

${ }^{21}$ Y. Tomida et al., Appl. Surf. Sci. 216, 502 (2003).

${ }^{22}$ F. Lee, T. R. Gow, and R. I. Masel, J. Electrochem. Soc. 136, 2640 (1989).

${ }^{23}$ F. Lee, A. L. Backman, R. Lin, T. R. Gow, and R. I. Masel, Surf. Sci. 216, 173 (1989).

${ }^{24}$ C. R. Flores, X. L. Zhou, and J. M. White, Surf. Sci. 261, 99 (1992).

${ }^{25}$ A. Forster and H. Luth, J. Vac. Sci. Technol. B 7, 720 (1989).

${ }^{26}$ K. Fukui, W. Mizutani, H. Onishi, S. Ichimura, H. Shimizu, and Y. Iwasawa, Jpn. J. Appl. Phys. 34, 4910 (1995).

${ }^{27}$ L. A. Cadwell and R. I. Masel, Surf. Sci. 318, 321 (1994).

${ }^{28}$ X. Y. Zhu, J. M. White, and J. R. Creighton, J. Vac. Sci. Technol. A 10, 316 (1992).

${ }^{29}$ J. R. Creighton, Surf. Sci. 234, 287 (1990).

${ }^{30}$ Z. M. Liu, X. L. Zhou, and J. M. White, Appl. Surf. Sci. 52, 249 (1991).

${ }^{31}$ C. Ozgit, I. Donmez, M. Alevli, and N. Biyikli, J. Vac. Sci. Technol. A 30, 01A124 (2012).

${ }^{32}$ B. H. Cardelino and C. A. Cardelino, J. Phys. Chem. C 113, 21765 (2009).

${ }^{33}$ B. H. Cardelino and C. A. Cardelino, J. Phys. Chem. C 115, 9090 (2011).

${ }^{34}$ D. H. Kang and M. Trenary, Surf. Sci. 470, L13 (2000).

${ }^{35}$ S. Otani, M. M. Korsukova, and T. Mitsuhashi, J. Cryst. Growth 186, 582 (1998).

${ }^{36}$ T. Aizawa, W. Hayami, and S. Otani, J. Chem. Phys. 117, 11310 (2002).

${ }^{37}$ W. Walkosz, K. Manandhar, M. Trenary, S. Otani, and P. Zapol, Surf. Sci. 606, 1808 (2012).

${ }^{38}$ K. Manandhar, W. Walkosz, M. Trenary, S. Otani, and P. Zapol, Surf. Sci. 615, 110 (2013).

${ }^{39}$ R. Singh, M. Trenary, and Y. Paderno, Surf. Sci. Spectra 7, 310 (2000).

${ }^{40}$ Y. Kawaguchi, A. Kobayashi, J. Ohta, and H. Fujioka, Jpn. J. Appl. Phys. 45, 6893 (2006).

${ }^{41}$ Z. T. Wang, Y. Yamada-Takamura, Y. Fujikawa, T. Sakurai, Q. K. Xue, J. Tolle, J. Kouvetakis, and I. S. T. Tsong, J. Appl. Phys. 100, 033506 (2006). 
${ }^{42}$ S. Kvisle and E. Rytter, Spectrochim. Acta A 40, 939 (1984).

${ }^{43}$ G. E. Coates and A. J. Downs, J. Chem. Soc. 3353 (1964).

${ }^{44}$ D. B. Mawhinney, J. A. Glass, Jr., and J. T. Yates, Jr., J. Vac. Sci. Technol. A 17, 679 (1999).

${ }^{45}$ M. P. S. D. Briggs, Practical Surface Analysis by Auger, and X-ray Photoelectron Spectroscopy (John Wiley \& Sons, New York, 1983).

${ }^{46}$ R. Larciprete, A. Goldoni, A. Groŝo, S. Lizzit, and G. Paolucci, Surf. Sci. 482-485, 134 (2001).

${ }^{47}$ S. Shogen, Y. Matsumi, M. Kawasaki, I. Toyoshima, and H. Okabe, J. Appl. Phys. 70, 462 (1991).

${ }^{48}$ J. F. Moulder, W. F. Stickle, P. E. Sobol, and K. D. Bomben, Handbook of $X$-ray Photoelectron Spectroscopy (Perkin-Elmer Corporation, Minnesota, 1992).
${ }^{49}$ I. Jiménez, D. G. J. Sutherland, T. van Buuren, J. A. Carlisle, L. J. Terminello, and F. J. Himpsel, Phys. Rev. B 57, 13167 (1998).

${ }^{50}$ W. C. Foo, J. S. Ozcomert, and M. Trenary, Surf. Sci. 255, 245 (1991).

${ }^{51}$ J. R. Creighton, B. A. Bansenauer, T. Huett, and J. M. White, J. Vac. Sci. Technol. A 11, 876 (1993).

${ }^{52}$ C. R. Abernathy and W. S. Hobson, J. Mater. Sci.: Mater. Electron 7, 1 (1996).

${ }^{53}$ N. Kobayashi and T. Makimoto, Jpn. J. Appl. Phys., Part 2. 24, L824 (1985).

${ }^{54}$ N. Kobayashi and T. Fukui, Electron. Lett. 20, 887 (1984).

${ }^{55}$ P. Norris, J. Black, S. Zemon, and G. Lambert, J. Cryst. Growth 68, 437 (1984). 